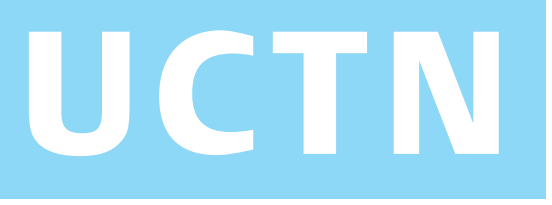

\title{
Diagnosis of an unusual tumor in the duodenum
}

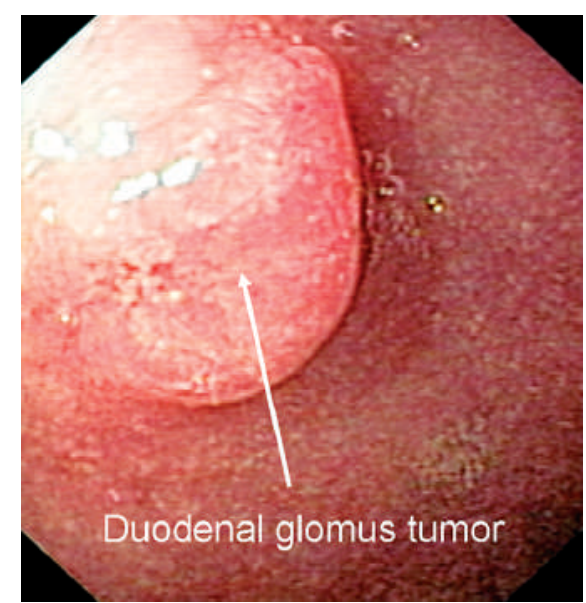

Figure 1 Endoscopic view of the glomus tumor.

A 65-year-old patient was admitted with repeated vomiting and suspected upper gastrointestinal bleeding. He had a known history of acute bleeding of an ulcer of the ileocoecal region, which had to be treated surgically. An esophagogastroduodenoscopy demonstrated a gastric ulcer (Forrest III; Helicobacter pylori negative), and Mallory-Weiss lesions covered with fibrin, with hemorrhagic reaction of the surrounding tissue; there was no sign of acute bleeding. Furthermore, a polyp in the duodenal bulb was seen (Figure 1), which was considered to be of inflammatory origin. Multiple biopsies were taken.

The histological examination of the duodenal polyp (Figure 2 ) revealed duodenal mucosa with foveolar gastric metaplasia and regional angiomatous proliferation. There were monomorphic cell clusters, with monomorphic nuclei and eosinophilic cytoplasm. The immunohistochemical staining showed no definite reaction for antibodies against CD34 or smooth muscle actin. The marker for proliferation MIB1 did not demonstrate any significant proliferation. Furthermore, the cells were negative for SMA, CD117, and CD56. There was no sign of malignancy. In summary, these cells represent a duodenal glomus tumor (GT). An endoscopic mucosal resection was then carried out, and confirmed the diagnosis.
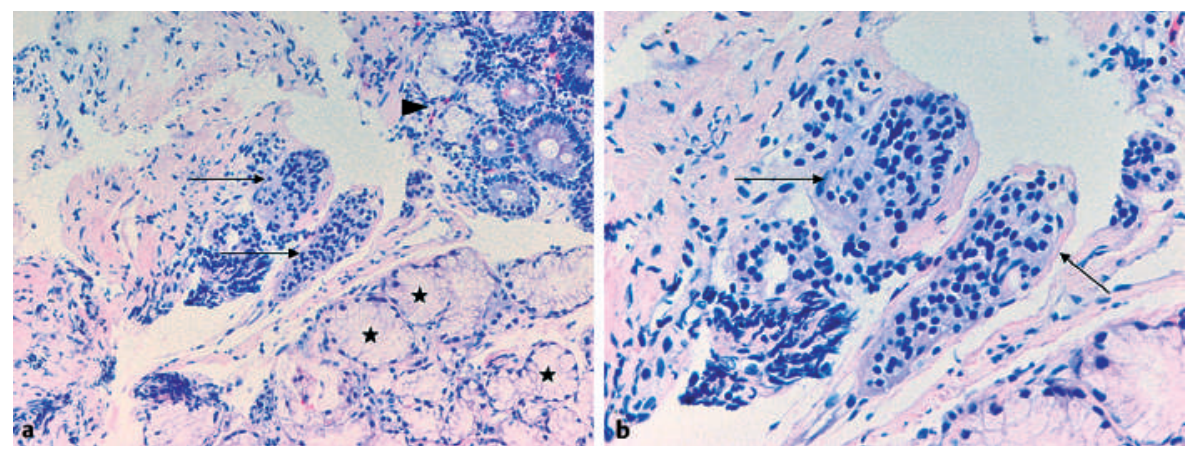

Figure 2 Histological sample of the glomus tumor. Glomangioma cell nests (arrows) in a vessel-wall. Basal part of the duodenal mucosa (arrow head). Asterisk, Brunner's glands.

Although the small intestine accounts for about $90 \%$ of the surface of the small bowel intestine tumors are rare [1]. Most frequently, these tumors are adenomatous or hyperplastic polyps, lipomas, or arteriovenous malformations [2]. GTs are mesenchymal tumors consisting of modified smooth muscle cells, representing a neoplastic counterpart of the perivascular glomus bodies [3]. Most commonly, these tumors occur in the distal parts of the extremities but have also been described in the stomach, and small and large intestine [4]. Therefore, GT represents a rare differential diagnosis that has to be considered [5]. Usually, they are benign; however, long-term follow-up data are not described, and there is no standardized management [4]. The patient was advised to undergo at least yearly gastroscopies; the 1-year follow-up was unremarkable.

Endoscopy_UCTN_Code_CCL_1AB_2AZ_3AB

\section{Knackstedt ${ }^{1}$, H. Wasmuth ${ }^{2}$,}

A. Donner ${ }^{3}$, C. Trautwein ${ }^{2}$, R. Winograd ${ }^{2}$

${ }^{1}$ Department of Cardiology, RWTH

University Aachen, Germany

2 Department of Gastroenterology, RWTH

University Aachen, Germany

${ }^{3}$ Department of Pathology, RWTH

University Aachen, Germany.

\section{References}

${ }^{1}$ DiSario JA, Burt RW, Vargas $\mathrm{H}$ et al. Small bowel cancer: epidemiological and clinical characteristics from a population-based registry. Am J Gastroenterol 1994; 89: 699-701

${ }^{2}$ Minardi AJ, Zibari G, Aultan DF et al. Smallbowel tumors. J Am Coll Surg 1998; 186: 664-668

${ }^{3}$ Tsuneyoshi M, Enjoji M. Glomus tumor: a clinicopathologic and electron microscopic study. Cancer 1982; 50: $1601-1607$

${ }^{4}$ Miettinen M, Paal E, Lasota J et al. Gastrointestinal glomus tumors. Am J Surg Pathol 2002; 26: $301-311$

5 Jundi M, Lack EE, Brun EA et al. Glomus tumor of the duodenum: a case report. Int J Surg Path 2004; 12: 411 - 414

\section{Corresponding author}

\section{R. Winograd, MD}

Department of Gastroenterology RWTH University Aachen

Pauwelsstr. 30

52074 Aachen

Germany

Fax: $\quad+49-241-80-82455$

Email: rwinograd@ukaachen.de 